\title{
Surface Wettability-Enhanced Electrochemical Detection of Hydrogen Peroxide
}

\author{
Xiaoxia Su, Xiaomei Dong, Huile Jin", Tianqi Zhu, Chengzhan Yan, Aili Liu, Shun Wang* \\ College of Chemistry and Materials Engineering, Wenzhou University, Wenzhou 325035, P. R. China \\ *E-mail: huilejin@wzu.edu.cn; shunwang@wzu.edu.cn;
}

doi: $10.20964 / 2017.05 .75$

Received: 8 February 2017 / Accepted: 13 March 2017 / Published: 12 April 2017

\begin{abstract}
A sensitive electrochemical sensor for the detection of hydrogen peroxide was fabricated in this study through manifesting surface wettability and morphology. Electrochemical measurements illustrate that a hydrophilic surface led to stronger electrocatalytic response of $\mathrm{Pt}$ to $\mathrm{H}_{2} \mathrm{O}_{2}$, yielding a sensitivity of $122.6 \mu \mathrm{A} \cdot \mathrm{mM}^{-1} \cdot \mathrm{cm}^{-2}$ within the concentration range between 40 and $500 \mathrm{nM}$. The achieved low detection limit is $12.8 \mathrm{nM}$. The hydrophilic surface also exhibits positive influences on the selectivity of $\mathrm{H}_{2} \mathrm{O}_{2}$ over ascorbic acid and ethanol. The observation highlights the importance of macroscopic properties such as surface wettability in the development of sensitive and selective chemical sensors.
\end{abstract}

Keywords: Surface wettability, Electrochemical catalysis, Hydrogen peroxide, Pt nanoparticle.

\section{$\underline{\text { FULL TEXT }}$}

(C) 2017 The Authors. Published by ESG (www.electrochemsci.org). This article is an open access article distributed under the terms and conditions of the Creative Commons Attribution license (http://creativecommons.org/licenses/by/4.0/). 